\title{
Is Shared Decision Making a Utopian Dream or an Achievable Goal?
}

\author{
Louisa Blair · France Légaré
}

Published online: 14 February 2015

(C) Springer International Publishing Switzerland 2015

\begin{abstract}
The idea of shared decision making (SDM) between patient and physician grew out of a generalized challenge to traditional social hierarchies that occurred in the middle of the last century. Governments have espoused SDM, thousands of articles about it have been published, and evidence has shown that it improves some of the healthcare processes as well as patient outcomes. Yet it has not been widely adopted. From their cross-disciplinary perspective (practical theology and clinical medicine), the authors locate this reluctance in the unfolding of scientific paradigm shifts, summarize the perceived risks and benefits of SDM and the evidence for each, and suggest practical, achievable approaches for clinicians. Finally, they explore some important emerging territories for SDM.
\end{abstract}

\footnotetext{
L. Blair

Department of Practical Theology, Faculté de théologie et de sciences religieuses, Université Laval, Pavillon Félix-Antoine-Savard, 2325, rue des Bibliothèques, Quebec, QC G1V 0A6, Canada

F. Légaré

CHU de Quebec Research Centre, Hôpital Saint-François

d'Assise, 10, rue de l'Espinay, Quebec, QC G1L 3L5, Canada

F. Légaré $(\bowtie)$

Canada Research Chair in Implementation of Shared Decision Making in Primary Care, Université Laval, Quebec City, Canada e-mail: france.legare@mfa.ulaval.ca
}

\section{Key Points for Decision Makers}

Shared decision making (SDM) has proved its worth and is achievable ... but debates continue.

Several validated models are available right now for use in clinical practice.

People can and are being successfully trained in SDM.

SDM is needed to address emerging value-laden clinical decisions such as those about caring for the elderly and about genetic testing.

\section{Take the Patient's History}

In 1868, the Canadian Medical Association's original Code of Ethics clearly laid out the patient's role in the patientdoctor relationship: "The obedience of a patient to the prescriptions of his physician should be prompt and implicit. [The patient] should never permit his own crude opinions as to their fitness to influence his attention to them" [1]. Over a century later, Harvey Picker expressed the tectonic shift in the patient-doctor relationship that began about a century later with his slogan "no decision about me, without me" [2].

This shift emerged from a broad-based social movement around gender and race that applied insights about the implications of human dignity and equality to longstanding social and political structures and institutional norms. The idea of consent appeared at least as early as 1911, when physician George Gay said in court that "everyone knows 
it to be a well-established fact that a person in his right mind has a right to decide as to whether any operation shall be performed upon himself" [3]. The term informed consent officially came into being in 1957 and has been defined as a reasoned choice made by a reasonable individual using relevant information about the advantages and disadvantages of all the possible courses of action, in accord with his or her beliefs $[3,4]$. This model was not yet interactive, i.e. it still assumed a certain passivity on the part of the patient, and did not make explicit the importance of patient values and preferences. However, the definition has evolved since then. In 1970, a 'patient-centered' model of medicine, as opposed to an illness-centered or doctorcentered model, was proposed by Michael Balint [5].

However, this movement was not only generated by doctors or academics. Around the same time, a group of women in Boston published a booklet entitled Women and their Bodies, in which the authors critiqued a medical system in which patients were discouraged from asking questions and were always dependent on the opinions and instructions of experts [6]. The booklet sold 200,000 copies by word of mouth alone, and their subsequent publication, Our Bodies Ourselves, sold millions [7]. Women, they said, had a right to know about controversies surrounding medical practices and about where consensus among medical experts may be forming [8]. What they were demanding-translated into the language of knowledge translation (KT), or KT-speak-was transfer of evidencebased knowledge about treatment options to relevant stakeholders. Their claims were upheld by scientific findings, such as an epidemic of unneeded surgical interventions [9]. John Wennberg's [10] work on practice variation in the USA showed that medical treatments provided had more to do with subjective factors related to the attitudes of individual physicians, or what he called the "practice style factor", than with patient or population characteristics, or with solid medical evidence. The 1989 Medical Outcomes Study, involving 22,462 patients in three US cities, demonstrated that there was a marked difference between patients' and physicians' perceptions of outcomes, and that involving patients can improve those outcomes [11]. In other words, these problems could only be addressed by rethinking the nature of the doctor-patient relationship itself.

This revolution would also involve changing communication strategies. Balint's successors identified shared decision making (SDM) as one of the ways in which physician and patient could find the "common ground" needed for patient-centered medicine, or what Ian McWhinney has called the "exchange and synthesis of meanings" necessary to break the linear mechanical logic of Cartesian medicine and face together the complexity of the human experience of illness [12].

\section{Define the Problem}

SDM, first formally defined in 1982 [13], is a form of informed decision making (IDM) that takes place in the clinical setting (IDM also applies to communities or healthcare systems) that is explicitly interactive and balances evidence with values [14]. In SDM, patient and doctor relate to and influence each other as they work together to make a decision about the patient's health. SDM takes into account the medical evidence, the doctor's clinical expertise, the patients' values and preferences, and the unique attributes of the patient and his or her family, such as cultural or linguistic affinity and mutual trust [15]. SDM often involves the use of decision aids, which are leaflets or online tools that present the evidence briefly and clearly and help patients clarify their preferences and values regarding the treatment. It is most appropriate in situations where there is clinical uncertainty, ambiguity, or simply an absence of sufficient evidence. Probabilities of risks and benefits in a population as a whole, for example, cannot always be directly applied to the individual patient. SDM is appropriate when there is "equipoise" [16, 17], i.e. when evidence for benefits and harms is closely balanced. In these situations, the patient's preferences play an important role-for example a woman with breast cancer deciding whether to have a mastectomy in the face of equal harms and benefits must consider what is most important to her.

Public policy supports for encouraging patient involvement in decision making are now in place in at least 13 countries [18]. Since 1989, more than 2,300 peer-reviewed articles have been published about the theory and practice of SDM, and the production of decision aids has flourished $[19,20]$.

\section{Determine the Decision to be Made}

One apparent difficulty in achieving the goal of SDM is that there is no single shared definition of SDM. Discussion continues about whether broader or narrower definitions should prevail and what precise skills SDM requires of physicians $[21,22]$. Some argue that patients do not necessarily want to share decisions-they want the doctor to make the decision for them [23]. At the other end of the spectrum, critics charge that patients can choose harmful or ruinously expensive options unchallenged by their physicians [24]. Some argue that only the rich and highly educated can engage in SDM because they are better equipped to understand the evidence and assert their preferences, and that if SDM is appropriated by a culture of 'mandatory autonomy' it will only benefit the powerful $[25,26]$. 


\section{Evidence of Risks and Benefits}

SDM researchers have addressed many of these more ethical or theoretical arguments [27]. When SDM is appropriate, but the patient chooses an option the healthcare professional does not consider beneficial (or legal), he/she can disagree. Both partners in the consultation need to be engaged in the decision, and SDM does not remove the responsibility of the healthcare professional to provide clear recommendations-on the contrary [28, 29]. However, if these options have been discussed to the satisfaction of both parties, litigation is less likely to occur and patients are more likely to follow the recommendations $[30,31]$. Patients by and large do want to participate in decisions, but we need to distinguish between situations that require problem solving and those that require decision making [32]. As for SDM being only for the rich, in fact it seems to benefit disadvantaged groups the most [33]. Davies and Elwyn [34] propose that "optional autonomy" is more appropriate in SDM, i.e. doctors ascertain what role patients want to play in the decision.

Then there are the practical objections: SDM would take too long [35], decisions involve whole professional teams and this makes SDM too complicated [36], SDM makes patients anxious and insecure [27]. Evidence to support these objections is slim. Although consultation length varies depending on the context, no-one has yet proved that SDM systematically takes longer [37-39]. Models for interprofessional SDM have been developed and are being tested [40, 41]. As for patient insecurity, this can be measured (e.g. the decisional conflict scale), and validated tools have been developed to help reduce it [39]; studies show that more equality between patient and doctor increases patient satisfaction [42].

A frequent argument is that SDM is too expensive, or that patients might choose an option that is risky, less efficacious, or more expensive. There is as yet little evidence on the overall costbenefits of SDM [43, 44], although the proponents of SDM have been accused of using SDM to ration healthcare [26]. It is important to consider the context of overuse, underuse, or misuse of treatments in assessing evidence of its effectiveness. Studies have generally focused on contexts of overuse (e.g. antibiotic prescriptions), in which SDM does appear to increase the choice for treatments that benefit the majority and reduce unwarranted practice variations [45]. Decision aids, too, the principal tool used in SDM, seem to reduce over-diagnosis and over-treatment [39, 46]. But as few studies have focused on contexts of underuse (e.g. pneumococcal vaccination), it is premature to pronounce on whether SDM is effective in all contexts at increasing the choice for options that are associated with increased benefits for all [44]. There is thus a need for further research on the impacts of SDM, and on all the barriers to SDM, real or perceived, to advance the participation of patients in decision making [31]. Ethical, theoretical, and practical debates around SDM are important. They are also inevitable. Just as in SDM itself, the precise balance between one model and another is likely to depend on the characteristics, preferences-and budgets-of everyone involved. Let the debates proceed: the goals of SDM are not all achievable yet.

\section{Eliciting Values and Preferences}

Thus, SDM is complex and controversial, but it is utopian for the public to continue to believe that every single patient who enters the doctor's office will always benefit from a treatment. Indeed, according to the BMJ Clinical Evidence summary, $89 \%$ (of 3,000 treatments) do not have clear benefits for the majority [47]. In addition to a shortage of relevant evidence, there is also the fact that evidence is probabilistic (i.e. out of $\mathrm{xx}$ patients, yy will benefit from a treatment—but we do not know which patients these are).

SDM has proved itself as an approach to addressing these vast areas of uncertainty, but there is still a worrying reluctance to put it into practice [48]. Are we still struggling to change our ideas about patient obedience nearly 150 years after the Canadian Medical Association published its Code of Ethics? Perhaps evidence is not enough to convince us-as many sociologists have pointed out. Rogers' diffusion of innovations theory explains that innovations that depart from centuries-old traditions can be slow to take hold, and require innovators to spread them $[49,50]$. In Kuhn's theory of paradigm shifts, old models that no longer adequately account for anomalies are slowly replaced with new [51].

\section{Making a Good Decision and Not Regretting It}

Those who see the need to shift away from hierarchical structures that assumed a caste system (women/men, Black/White, patient/healthcare professional) may be discouraged or blocked by the contradictions-they may have decisional conflict. There are feminists, for example, whose dreams were defeated when liberated mothers in the North American workforce began to hire third-world nannies who left their own children to be raised by their grandmothersonly available for the task because they are from traditional pre-feminist cultures [52]. But, if we trust that the original insight was correct and important, we can continue to test it, address each anomaly or challenge as it arises in the spirit of the original insight, and at the same time seek practical solutions and implement them in the real world 
[53]. SDM is a utopian dream only in the sense that Martin Luther King's was.

\section{Following Through with the Decision}

Meanwhile, many researchers have developed practical tools to help clinicians and patients engage in SDM. In 2006, Makoul and Clayman [28] outlined the essential elements by integrating all the notions they found in an extensive literature search: explain the problem; present options; discuss pros and cons; elicit patient preferences; discuss patient ability; doctor's recommendations; check understanding; make or defer the decision; arrange followup. Each one of these elements can be translated into an SDM-related clinical behaviour [54]. More recently, Elwyn et al. [55] proposed a model based on three "talk" moments: choice talk, option talk, and decision talk. Shepherd et al. [56] took the patient's point of view and showed that three simple questions (What are my options? What are the possible benefits and harms of my options? And how likely are each of these to occur?) could improve information given by family physicians and increase their facilitation of patient involvement.

Second, our research has shown that both doctors in training and practising doctors can be taught to share decisions with their patients [57]. The number of training programs in SDM is increasing exponentially worldwide [58], but they are so heterogeneous that it is still hard to say what kind of training works best and, at the minimum, what an effective program needs to include. However, a recent Cochrane review suggests that any training is better than none, and that programs targeting both patients and physicians are more promising than those targeting one or the other. Linked to (and often part of) training programs, decision aids are also proliferating [20], and a Cochrane review has shown that they improve people's knowledge regarding options and reduce their decisional conflict related to feeling uninformed and unclear about their personal values [39].

\section{Follow-Up}

As we solve some of the obstacles to achieving the goals of SDM, we encounter new challenges, which lead us practical dreamers to new areas of exploration. Most importantly, we need to broaden our perspective on the stakeholders in the decision. For example, the family caregivers of elderly patients living at home are important players in decision making about treatments or management options for those patients. Our research on sharing decisions about the relocation of frail elderly people being cared for at home to long-term care facilities suggests that the values and preferences of family caregivers may be deeply conflicted: while they believe that the patient should be involved in this difficult decision, they are often elderly persons themselves, with their own health issues, who may be physically or emotionally overwhelmed by the patients' needs [59]. Clarifying their role in the decision-making process and exploring how health professionals can support them in reconciling their needs and preferences with those of their relatives is a complex and yet vital next step in SDM research with this population.

Our team is also exploring SDM in the context of newly available genetic testing options. Our society's ability to perform predictive genetic testing has outstripped its ability to manage the consequences. Genetic testing implies new kinds of options, new kinds of decisions, and therefore new implications for how to share them. The most familiar example is that of a pregnant woman who has to decide whether or not to undergo a prenatal genetic test. The consequence of choosing to do the test will be a decision about whether or not to do a more invasive diagnostic test, and the consequence of choosing to do that diagnostic test may be a decision about whether or not to terminate the pregnancy. The last decision is a more value-laden decision than the first, yet the process began with a decision for which the pros and cons of each option were relatively simple. Our focus in SDM has been to communicate evidence about the pros and cons of the options while trying to find ways to clarify values. But if we are serious about patient values, as genetic testing becomes more widespread in every domain, we may need to also calculate the weight of the benefits and risks of each option in terms of the number and nature of further options and decisions it will entail.

Moreover, genetic testing confronts us with a crying lack of evidence. Our search for decision aids that might assist physicians presenting options about a recently available prenatal test, for example, has found not a single relevant study. How should physicians support patients in choosing among 'no-data' options? How can doctors and their patients weigh the benefits and risks of a predictive test for diseases for which there is no data-and moreover, perhaps no cure?

Where there is not so much a grey zone of evidence but rather no evidence at all, not just the preferences of patients but also their belief systems will play an increasing role in decision making. The day when physicians make decisions for their patients is long past-the genie escaped from the bottle years ago [60]. We need to face these new challenges with courage, returning to our original inspiration for new energy, turning to the literature for new evidence, and working towards making respect, sensitivity, and empathy towards the patient a reality in daily practice — and if that 
sounds highly preference-sensitive, there is evidence that SDM is an 'effective' treatment, i.e. that with SDM, outcomes may be better $[39,61]$. As we say in Quebec, on lâche pas! ${ }^{1}$

Conflict of interest statements Louisa Blair declares no conflict of interest. France Légaré is holder of the Canada Research Chair in Implementation of Shared Decision Making in Primary Care.

Authors' contributions Both Louisa Blair and France Légaré collaborated in all phases of the preparation of this manuscript from conception to final draft.

France Légaré is the guarantor of the paper.

\section{References}

1. Code of ethics of the Canadian Medical Association adopted Sept. 1868.

2. Coulter AC, Collins A. Making shared decision-making a reality: no decision about me, without me. The King's Fund; 2011.

3. Faden RR, Beauchamp TL, King NMP. A history and theory of informed consent, vol. 15. New York: Oxford University Press; 1986. p. 392.

4. Bekker H, Thornton JG, Airey CM, Connelly JB, Hewison J, Robinson $\mathrm{MB}$, et al. Informed decision making: an annotated bibliography and systematic review. Health Technol Assess. 1999;3(1):1-156.

5. Balint M. Treatment or diagnosis; a study of repeat prescriptions in general practice. London, Philadelphia: Tavistock Publications, J.B. Lippincott; 1970.

6. Boston Women's Health Course C. Women and their bodies : a course. Boston: Boston Women's Health Collective; 1970.

7. Collective BWsH. Our bodies, ourselves. New York: Simon \& Schuster; 1973.

8. Millenson ML. Spock, feminists, and the fight for participatory medicine: a history. J Participat Med. 2011;3:e27 (Epub Jun 21).

9. Leape LL. Unnecessary surgery. Health Serv Res. 1989;24(3): 351-407 (Epub 1989/08/01).

10. Wennberg JE. Dealing with medical practice variations: a proposal for action. Health Affairs (Project Hope). 1984;3(2):6-32 Epub 1984/01/01.

11. Tarlov AR, Ware JE Jr, Greenfield S, Nelson EC, Perrin E, et al. The medical outcomes study: an application of methods for monitoring the results of medical care. JAMA. 1989;262(7):925-30.

12. Stewart M. Patient-centered medicine : transforming the clinical method. Abingdon: Radcliffe Med. Press; 2003.

13. The President's Commission for the Study of Ethical Problems in Medicine and Biomedical and Behavioral Research. A Report on the ethical and legal implications of informed consent in the patient-practitioner relationship. Washington, DC; 1982.

14. Briss P, Rimer B, Reilley B, Coates RC, Lee NC, Mullen P, et al. Promoting informed decisions about cancer screening in communities and healthcare systems. Am J Prev Med. 2004;26(1):67-80.

15. Légaré F, Witteman HO. Shared decision making: examining key elements and barriers to adoption into routine clinical practice. Health Affairs (Project Hope). 2013;32(2):276-84 (Epub 2013/02/06).

16. Pauker SG, Kassirer JP. Contentious screening decisions: does the choice matter? N Eng J Med. 1997;336(17):1243-4.

\footnotetext{
${ }^{1}$ We're not quitting!
}

17. Elwyn G, Edwards A, Kinnersley P, Grol R. Shared decision making and the concept of equipoise: the competences of involving patients in healthcare choices. $\mathrm{Br} J$ Gen Pract. 2000;50(460):892-9.

18. Harter M, van der Weijden T, Elwyn G. Policy and practice developments in the implementation of shared decision making: an international perspective. Z Evid Fortbild Qual Gesundheitswes. 2011;105(4):229-33.

19. Elwyn G, O’Connor A, Stacey D, Volk R, Edwards A, Coulter A, et al. Developing a quality criteria framework for patient decision aids: online international Delphi consensus process. BMJ. 2006;333(7565):417.

20. Koster J. PubMed PubReMiner version 1.14. Amsterdam, The Netherlands: Department of Oncogenomics, AMC; 2014 [cited 20145 August]; Available from: http://hgserver2.amc.nl/cgi-bin/ miner/miner2.cgi. Accessed 5 Aug 2014.

21. Légaré F, Moumjid-Ferdjaoui N, Drolet R, Stacey D, Harter M, Bastian H, Beaulieu M-D, et al. Core competencies for shared decision making training programs: insights from an international, interdisciplinary working group (1554-558X (electronic)).

22. Cribb A, Entwistle VA. Shared decision making: trade-offs between narrower and broader conceptions. Health Expect Int J Public Particip Health Care Health Policy. 2011;14(2):210-9 Epub 2011/05/20.

23. Woolf SH. Editorial: the logic and limits of shared decision making. J Urol. 2001;166(1):244-5.

24. Buetow S, Kenealy T. Ideological debates in family medicine. New York: Nova Biomedical Books; 2007.

25. Kiesler DJ, Auerbach SM. Optimal matches of patient preferences for information, decision-making and interpersonal behavior: evidence, models and interventions. Patient Educ Couns. 2006;61(3):319-41 Epub 2005/12/22.

26. Elwyn G, Tilburt J, Montori V. The ethical imperative for shared decision-making. Eur J Pers Cent Healthc. 2012;1(1):129-31.

27. Légaré F, Thompson-Leduc P. Twelve myths about shared decision making. Patient Educ Couns. 2014;96(3):281-6.

28. Makoul G, Clayman ML. An integrative model of shared decision making in medical encounters. Patient Educ Couns. 2006;60(3): 301-12.

29. Coulter A. Partnerships with patients: the pros and cons of shared clinical decision-making. J Health Serv Res Policy. 1997;2(2): $112-21$.

30. Légaré F, Boivin A, van der Weijden T, Pakenham C, Burgers J, Légaré J, et al. Patient and public involvement in clinical practice guidelines: a knowledge synthesis of existing programs. Med Decis Making. 2011;31(6):E45-74.

31. Gattellari M, Butow PN, Tattersall MHN. Sharing decisions in cancer care. Social Sci Med. 2001;52(12):1865-78.

32. Deber RB, Kraetschmer N, Urowitz S, Sharpe N. Do people want to be autonomous patients? Preferred roles in treatment decisionmaking in several patient populations. Health Expect Int J Public Particip Health Care Health Policy. 2007;10(3):248-58 Epub 2007/08/07.

33. Durand MA, Carpenter L, Dolan H, Bravo P, Mann M, Bunn F, et al. Do interventions designed to support shared decisionmaking reduce health inequalities? A systematic review and meta-analysis. PloS One. 2014;9(4):e94670 (Epub 2014/04/17).

34. Davies M, Elwyn G. Advocating mandatory patient 'autonomy' in healthcare: adverse reactions and side effects. Health Care Anal HCA J Health Philos Policy. 2008;16(4):315-28 Epub 2007/11/03.

35. King VJ, Davis MM, Gorman PN, Rugge JB, Fagnan LJ. Perceptions of shared decision making and decision aids among rural primary care clinicians. Medical Decis Making Int J Soc Med Decis Making. 2012;32(4):636-44 Epub 2012/01/17.

36. Puntillo KA, McAdam JL. Communication between physicians and nurses as a target for improving end-of-life care in the 
intensive care unit: challenges and opportunities for moving forward. Criti Care Med. 2006;34(11):332-40.

37. Légaré F, Ratte S, Stacey D, Kryworuchko J, Gravel K, Graham ID, et al. Interventions for improving the adoption of shared decision making by healthcare professionals. Cochrane Database Syst Rev. 2010(5):CD006732 (Epub 2010/05/14).

38. Légaré F, Turcotte S, Stacey D, Ratte S, Kryworuchko J, Graham ID. Patients' perceptions of sharing in decisions a systematic review of interventions to enhance shared decision making in routine clinical practice. Patient. 2012;5(1):1-19.

39. Stacey D, Légaré F, Col N, Bennett C, Barry M, Eden K, et al. Decision aids for people facing health treatment or screening decisions. Cochrane Database Syst Rev. 2014;1:CD001431.

40. Stacey D, Légaré F, Pouliot S, Kryworuchko J, Dunn S. Shared decision making models to inform an interprofessional perspective on decision making: a theory analysis. Patient Educ Couns. 2010;80(2):164-72 Epub 2009/12/01.

41. Légaré F, Stacey D, Gagnon S, Dunn S, Pluye P, Frosch D, et al. Validating a conceptual model for an inter-professional approach to shared decision making: a mixed methods study. J Eval Clin Pract. 2011;17(4):554-64 (Epub 2010/08/11).

42. Menzel H, Coleman J, Katz E. Dimensions of being modern in medical practice. J Chronic Dis. 1959;9(1):20-40.

43. Walsh T, Barr PJ, Thompson R, Ozanne E, O’Neill C, Elwyn G. Undetermined impact of patient decision support interventions on healthcare costs and savings: systematic review. BMJ. 2014;348: g188 Epub 2014/01/25.

44. Trenaman L, Bryan S, Bansback N. The cost-effectiveness of patient decision aids: a systematic review. Healthcare. 2014;2(4): 251-7.

45. Wennberg JE. Practice variation: implications for our health care system. Manag care. 2004;13(9 Suppl):3-7 (Epub 2004/10/21).

46. Evans R, Edwards A, Brett J, Bradburn M, Watson E, Austoker J, Elwyn G. Reduction in uptake of PSA tests following decision aids: systematic review of current aids and their evaluations. Patient Educ Couns. 2005;58(1):13-26.

47. BMJ CE. Efficacy categorisations. 2014; Available from: http:// clinicalevidence.bmj.com/x/set/static/cms/efficacy-categorisations. html. Accessed 21 Nov 2014.

48. Hoffman RM, Elmore JG, Fairfield KM, Gerstein BS, Levin CA, Pignone MP. Lack of shared decision making in cancer screening discussions: results from a National Survey. Am J Prev Med. 2014 (Epub 2014/06/14).

49. Denis JL, Hebert Y, Langley A, Lozeau D, Trottier LH. Explaining diffusion patterns for complex health care innovations. Health Care Manage Rev. 2002;27(3):60-73.
50. Rogers EM. Diffusion of innovations. 5th ed. India: Free Press; 2003.

51. Kuhn TS. The structure of scientific revolutions, vol. 15. Chicago: University of Chicago Press; 1962. p. 172.

52. Ehrenreich B, Hochschild AR. Global woman: nannies, maids, and sex workers in the new economy: Henry Holt and Company; 2004.

53. Frensch PA, Funke J. Complex problem solving the European perspective. Hoboken: Taylor and Francis; 2014; Available from: http://public.eblib.com/choice/publicfullrecord.aspx?p=1665695. Accessed 20 Nov 2014.

54. Frosch D, Légaré F, Fishbein M, Elwyn G. Adjuncts or adversaries to shared decision-making? Applying the Integrative Model of behavior to the role and design of decision support interventions in healthcare interactions. Implement Sci. 2009;4(1):73

55. Elwyn G, Frosch D, Thomson R, Joseph-Williams N, Lloyd A, Kinnersley P, et al. Shared decision making: a model for clinical practice. J Gen Intern Med. 2012;27(10):1361-7 Epub 2012/05/ 24.

56. Shepherd HL, Barratt A, Trevena LJ, McGeechan K, Carey K, Epstein RM, et al. Three questions that patients can ask to improve the quality of information physicians give about treatment options: a cross-over trial. Patient Educ Couns. 2011;84(3): 379-85.

57. Légaré $\mathrm{F}$, Labrecque $\mathrm{M}$, Cauchon $\mathrm{M}$, Castel $\mathrm{J}$, Turcotte $\mathrm{S}$, Grimshaw J. Training family physicians in shared decisionmaking to reduce the overuse of antibiotics in acute respiratory infections: a cluster randomized trial. CMAJ. 2012 (Epub 2012/08/01).

58. Légaré F, Politi MC, Drolet R, Desroches S, Stacey D, Bekker H. Training health professionals in shared decision-making: an international environmental scan. Patient Educ Couns. 2012 (Epub 2012/02/07).

59. Légaré F, Stacey D, Briere N, Robitaille H, Lord MC, Desroches $\mathrm{S}$, et al. An interprofessional approach to shared decision making: an exploratory case study with family caregivers of one IP home care team. BMC Geriatr. 2014;14(1):83 (Epub 2014/07/06).

60. Coulter A. Paternalism or partnership? Patients have grown up-and there's no going back [editorial; comment]. BMJ. 1999;319(7212):719-20.

61. Légaré F, Guerrier M, Nadeau C, Rheaume C, Turcotte S, Labrecque M. Impact of DECISION +2 on patient and physician assessment of shared decision making implementation in the context of antibiotics use for acute respiratory infections. Implement Sci. 2013;8(1):144. 